\title{
THE COLOR OF MASS INCARCERATION
}

\author{
Ronnie B. Tucker, Sr. \\ Shippensburg University
}

According to the United States Constitution, the Fourteenth Amendment provides "Equal Protection Under the Law;" as well as the "Right to Due Process." It is a generally accepted view that this amendment was implemented to ensure African Americans were treated fairly in the United States. It is an accepted practice that this amendment was implemented to bring about equality in segregated circumstances in this country. Nevertheless, the pivotal application of the Fourteenth Amendment is that of "The Right to Due Process." When one reviews the statistics of the current plight of African American men and women as well as those of Hispanics as it relates to the composition of the United States prison population; there are some serious issues that arise. The current composition of the United States prison population is a majority of the minority population. The "Color of Mass Incarceration" is that of non-white Americans. The issue of Mass Incarceration has even lead to the hypothetical concern as to whether or not this is another way of stifling the future increase of the African American population? This is an issue that will require strict attention in view of the rate of incarceration of African American men in this country. The concern of the "Color of Mass Incarceration" is further perpetuated when review is given to incarceration trends in America. For instance, from 1980 to 2008, the number of people incarcerated in America quadrupled-from roughly 500,000 to 2.3 million people (NAACP Criminal Justice Fact Sheet; 2009-2016).

African Americans now constitute nearly 1 million of the total 2.3 million incarcerated population. The incarceration rate of African Americans is nearly six times that of whites (NAACP Criminal Justice Fact Sheet; 2009-2016). As a matter of fact, if these trends continue in America, one in three African American men born today can expect to spend time in prison during their lifetime. There is also the disheartening fact that 1 in 100 African American women are in prison as well. In a national review, statistics reveal that, nationwide, African Americans represent $26 \%$ of juvenile arrest, $44 \%$ of youth who are detained, $46 \%$ of the youth who are judicially waved to criminal court, and $58 \%$ of the youth admitted to state prisons (Center on Juvenile and Criminal Justice). 


\section{The Definition of Mass Incarceration}

Mass incarceration is defined by historically extreme rates of imprisonment and by the concentration of incarceration among the most marginalized (Garland, 2001). Mass incarceration is the confinement of large numbers of people to prisons, and the subsequent legal and financial restrictions they face once they leave prison which prevent them from reentering mainstream society (Younes, 2014). It is important to note that the definition of "Mass Incarceration" is an inclusive and farreaching definition. The far-reaching perspectives of "Mass Incarceration" is that it presents a potential for the parental imprisonment of children (Wildeman, 2009), a geographic concentration of imprisonment in urban neighborhoods (Sampson and Leoffler, 2010), and the symbiotic relationship between the prison system and the American ghetto (Wacquant, 2001). There is also the unfortunate potential that the impact of mass incarceration will extend beyond the walls of the prison and impact other social controls (Simon, 1993).

There appears to be an indirect or even direct correlation between mass incarceration and the issue of drug usage among African Americans. Thus causing one to speculate as to whether or not mass incarceration is connected to drug use and drug crimes. The "War on Drugs" began as a "crackdown" on the drug dealers and drug abusers; however, statistics reflect that there is a disparity in drug sentencing that has provided a correlation to the number of African Americans being incarcerated. Studies reveal that about 14 million Whites and 2.6 million African Americans report using illicit drugs. While there are five times as many Whites using drugs as African Americans, African Americans are being sent to prison for drug offenses at 10 times the rate of Whites. When put into a statistical perspective, the results are: African Americans represent $12 \%$ of the total population of drug users, but $38 \%$ of those arrested for drug offenses, and $59 \%$ of those in state prison for drug offense. The telling result is that African Americans serve virtually as much time in prison for a drug offense (58.7 months) as whites do for violent offenses (61.7 months) (Sentencing Project). This point will be further explored under the discussion of the number of African Americans in prison for non-violent crimes.

When the issue of mass incarceration is studied, it reveals that there are over two million inmates giving the United States the world's highest imprisonment rate, higher than that of Iran and China. Given that African Americans make up only $12 \%$ of the United States population, but, together with Latinos, comprise over $60 \%$ of total inmate population, it is hypothesized that the color of mass incarceration is drawn from African American, Hispanic, and Native American populations. It is noteworthy that the United States current rate of imprisonment has a higher percent- 
age of African Americans than that of South Africa at the height of Apartheid, with one in every eight African American men behind bars (Younes, 2014). Given this assessment of the current rate of imprisonment of African Americans, there exists the potential that African American children born today are less likely to be raised by both parents than an African American child who was born in slavery.

Table 1: Basic Data on Prison Population in the United States

\begin{tabular}{|l|l|l|l|l|}
\hline Total Male & White & African Amer. & Latino/Hispanic & Other \\
\hline $1,402,404$ & 453,500 & 516,900 & 308,700 & 123,300 \\
\hline Total Female & White & African Amer. & Latino/Hispanic & Other \\
\hline 106,232 & 53,100 & 22,600 & 17,800 & 12,800 \\
\hline All Genders & White & African Amer. & Latino/Hispanic & Other \\
\hline $1,508,636$ & 559,732 & 539,500 & 326,500 & 136,100 \\
\hline
\end{tabular}

*Race and Prison- Drug War Facts- 2014

When reviewing the prison population in the United States, there are 435,500 White men imprisoned compared to 516,900 African American men. The next larger number of imprisoned men are Hispanics/Latinos at 308,700. Even though Hispanic/Latinos and African Americans are not the majority population, they do constitute the majority population within prisons. Table 1 indicates that there are, however, fewer African American and Hispanic/Latino women imprisoned than white women. The data in Table 1 includes those sentenced in State and Federal prisons in the United States as of December 31, 2014.

Table 2: Comparative Analysis

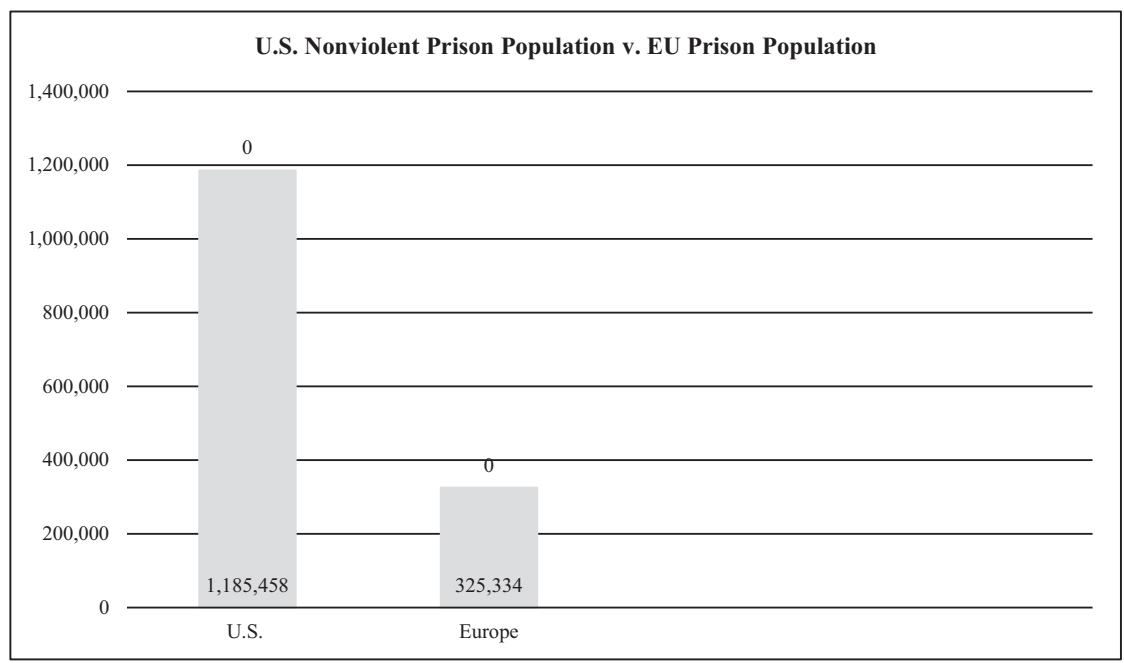


Comparing the nonviolent prisoners only with those of the European Union, Table 2 demonstrates that the United States has 1,185,458 nonviolent offenders which is five times the number of people detained in the European Union's entire prison system, 325,334. The United States also has a rate of six times higher than that of Canada, England, and France, and seven times higher than Switzerland and Holland, and ten times that of Sweden and Finland (Street, 2012). The composition of these nonviolent prisoners is that of primarily African American males. Thus, the looming assessment is that in the United States, incarceration is heavily racialized in nature. In view of the numbers previously stated, it is inferred that on any given day in the United States, thirty percent of African American males ages 20-29 are "under correctional supervision (Bureau of Justice).

\section{Mass InCARCERATION AND RACIALIZATION}

It was the expectation of many African Americans that the election of President Obama would bring the United States into a "post-racial" era. There were expectations that the election of the first African American president would signal a symbolic demise of Jim Crow era and that the social, political and cultural climate would improve. However, this expectation was quickly dashed as a Republican Congress determined to see the President fail, dug in their heels and basically did nothing for two years. In the midst of this, the expectation was further dashed by the fact that every state in the nation continues to have a disproportionately high percentage of African American men presently in prison. One year prior to the 2008 presidential election, roughly $35 \%$ of incarcerated men in federal and state prisons and jails were African American. Even though, African Americans comprise just over $12 \%$ of the total population. In 2010, the prison population declined for the first time since 1972 (Bureau of Justice Statistics). Nevertheless, this did not lead to a reduction in the incarceration rate for African American men, as studies reveal that African American men are imprisoned at an overall rate of nearly seven times that of white men (Bureau of Justice Statistics).

It becomes apparent that the high rate of incarceration among African American men is part of an overall trend in punishment defined by a dramatic increase in what is viewed as the "carceral system" (Foucault, 1975). It is clearly evident that the increased incarceration rate is more significant for African American men than any other segment of population with Hispanics coming in at a close second. According to the noted author, Michelle Alexander, "More African Americans are under correctional control today, in prison, jail, or probation, or on parole-than were enslaved in 1850 before the Civil War began (Alexander, 2010). Manning Marable identifies the criminal justice system as one of three pillars 
forming a deadly triangle of "institutional racism" (Marable, 2007). Alexander is in agreement with this statement and suggests that "mass incarceration has established a 'racial caste system' in society, primarily driven by politics, not crime (Alexander, 2010). It is as Alexander suggests, that the incarceration rate of African Americans is now the new "Jim Crow." There is also the matter that race has become embedded in the very principles of criminal law in the United States. Incarceration rates bring race into what might otherwise be viewed as a racially neutral process. The imposition of mass incarceration which is colored by minority population, especially African American men, brings with it social and residential segregation. It is understood that de jure segregation is unconstitutional but yet in the criminal justice system, it appears that de jure segregation is alive and doing very well! The segregation of African American males especially from society has a pervasive effect in that it spreads to many areas of life in the African American community.

\section{Statistical Overview of Mass Incarceration}

Today, people of color continue to disproportionately represent those being incarcerated, policed and sentenced to death at a much higher rate than whites. The statistics that relate to the color of mass incarceration have varied over the years, but with the same result that people of color constitute the color of mass incarceration. For example, it was revealed that an African American man born in 1991 had a 29\% chance of spending time in prison at some point in his life. During this same time period, it was predicted that one out of nine African American men would be incarcerated between the ages of 20-34. It was further stated that African American men ages 30-34 have the highest incarceration rate of any race, ethnicity, gender and age combination (American Community Survey). According to Fizen, "the lifetime chances of going to prison are $32.2 \%$ for African American males and 17.2\% for Latino males, while only $5.9 \%$ for white males" (Fizen, 1991). The statistics would change again for mass incarceration during the period of 2009. 
Table 3: Percentage of adult males incarcerated IN THE US IN 2009

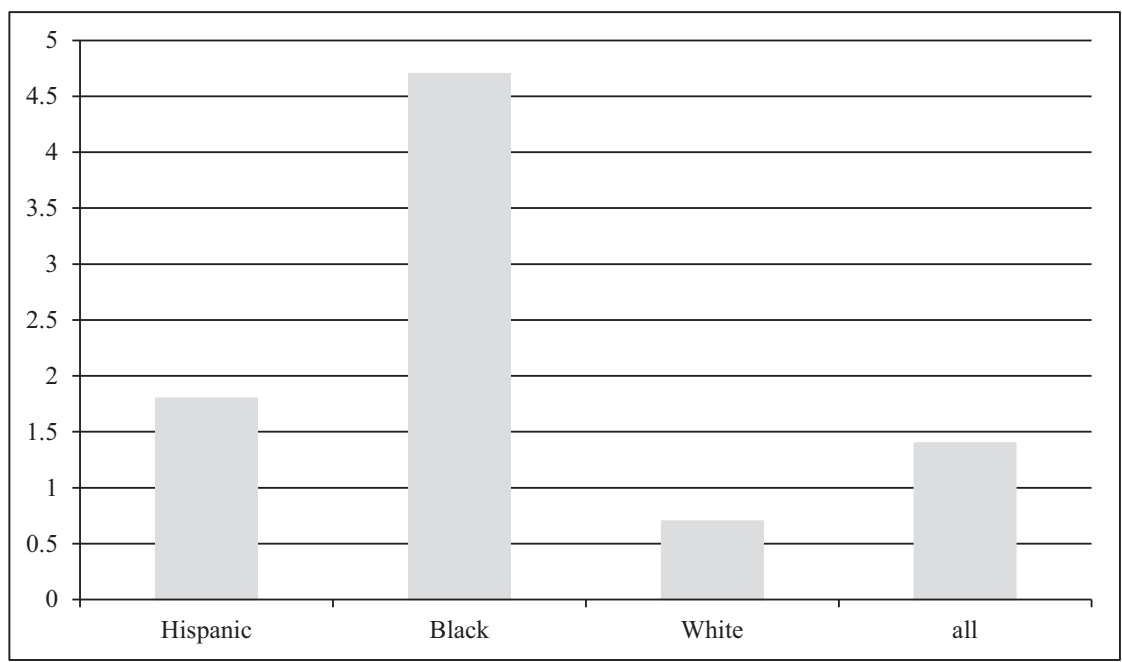

*Prison Inmates at Midyear 2009- NCJ

The inmate population in 2009 revealed that there were $1.8 \%$ Hispanic males, $4.7 \%$ African American males, while $0.7 \%$ were white males, and $1.4 \%$ of all adult males. There would be an interesting change in the prison population in 2013, however, the underlying fact would be that African Americans still have the highest incarceration rate and clearly exhibit the color of mass incarceration. It should be noted that during the period of 2010 and 2012, there was a continued substantial increase in mass incarceration, yet the end results remain the same. In 2013, African American males constituted 37\%, the largest percentage of male inmates under state or federal jurisdiction. That compares to Whites (32\%) and Hispanics (22\%). During this timeframe, white females comprised $49 \%$ of the prison population compared to 22\% African American females. The imprisonment rate for African American females (113 per $100,000)$ was twice the rate of white females (51 per 100,000) (Bureau of Justice Statistics). The Bureau of Justice Statistics noted that, "almost 3\% of African American male U.S. residents of all ages were imprisoned on December 31, 2013, compared to $0.5 \%$ of white males.

African American males had higher imprisonment rates across all age groups than other races and Hispanic males. In the age range with the highest imprisonment rates for males (ages 25-39), African American males were imprisoned at rate at least 2.5 times greater than Hispanic males and 6 times greater than white males. For ages 18-19, the age range with the greatest difference in imprisonment rates between whites and African Americans, African American males (115 inmates per 100,00 white males). In 2015 , the prison population increased to 2.2 mil- 
lion; with African Americans still constituting 40\% of the total prison population. The continued increase of African Americans in mass incarceration creates concerns regarding the manner in which policing is takes place and the manner in which the judicial system operates. The color of mass incarceration continues to be that of Black, Brown, and Red, with a sprinkle of Yellow mixed in.

\section{The Underlying Factor Leading to Mass Incarceration}

The numbers pertaining to the incarceration of African Americans are staggering, but yet they tell only a portion of the story. Since African Americans constitute the majority of the prison population, it would seem likely that they would represent proportionally large number of offenders in violent offenses as well. However, the majority of offenses committed by African Americans are nonviolent. As a matter of fact, the majority of African Americans in prison are there as a result of drugrelated offenses.

In view of the number of people of color in prison, it would seem that there would be a correlation between mass incarceration and violent offenders in prison. However, people of color are not the Ted Bundies or Charlie Mansons of our society. The people of color being incarcerated are not even the offenders who have committed sensationalized robberies, rapes, or murders. The bulk of the people of color who have fallen victim to mass incarceration are those who have been convicted of class $\mathrm{D}$ drug charges. The additional issue that increased the number of people of color incarcerated is the implementation of "Three Strikes" laws. Many of these offenders may even spend little time in prison, but yet they are labeled as drug offenders. It has been noted that the "War on Drugs" has in actuality translated into a "War on People of Color." As a result of the "War on Drugs," people of color have been the victims of collateral damage.

The war on drugs has been unfortunately waged primarily in communities of color where people of color are more likely to receive higher offenses. According to the Human Rights Watch, people of color are no more likely to use or sell illegal drugs than whites, but they have the higher rate of arrests. African Americans comprise 14\% of regular drug users but are $37 \%$ of those arrested for drug offenses (Human Rights Watch). Studies have shown that between 1980 and 2007, approximately one in three of the 25.4 million adults arrested for drugs were African Americans (Kerby, 2012). The color of mass incarceration is exacerbated due to the additional fact that once convicted African Americans receive longer sentences compared to white offenders. According to the U.S. Sentencing Commission, "in the federal system African American offenders receive sentences that are $10 \%$ longer than white offenders for 
the same crimes. The Sentencing Project reported that African Americans are $21 \%$ more likely to receive mandatory-minimum sentences than white defendants and are $20 \%$ more likely to be sentenced to prison. As a result of being incarcerated for a drug offense, many African Americans men and women are declared convicted felons, which translates into a period of disenfranchisement in many states.

It is suggested that African American and Latino drug dealers are more likely to be arrested because their drug activities are more likely to take place in "open air public" drug markets than white drug dealers. However, police elect to pursue open air drug markets with minority dealers and ignore those where whites are selling drugs. Hence the war on drugs has been especially hard on people of color as individuals and as a community. While the war on drugs has a high correlation to the number of people of color being incarcerated it is understood that this is the only factor contributing to mass incarceration. Consideration, nevertheless, needs to be given to creating a goal of equality of opportunity for all races, with the focus being the removal of the so-called "War on Drugs" and the dismantling of legal restrictions that prevent ex-prisoners from being able to function in society and attain food and shelter.

\section{The Gender Composition of InCARCERAtion}

Within the realm of mass incarceration is also the gender factor since African American women are also incarcerated. African American women comprise $30 \%$ of incarcerated women, although African America women represent only $13 \%$ of the nation's female population (The Pew Report). The rate of incarceration for women has increased at nearly double the rate of men since 1985, and the impact of the absence of these primary caregivers on families is devastating. Today, there are more than eight times as many women in prisons and jails than in 1980. The PEW Center reported in 2008 that 1 in 355 white women between the ages of 35-39 were imprisoned compared to 1 in 100 African American women. The likelihood of a woman of color being incarcerated is 1 in 19 for African Americans and 1 in 15 for Hispanics, compared to only 1 in 118 for whites. In 2010, African American women were incarcerated at nearly 3 times the rate of white women (133 versus 47 per 100,000). Hispanic women were incarcerated at 1.6 times the rate of white women (77 versus 47 per 100,000). Studies revealed that from 2000 to 2010, the rate of incarceration decreased 35\% for African American women and increased $28 \%$ for Hispanic women, and $38 \%$ for white women (Guerino, 2011). 
Female Incarceration Rate by Race, 2000-2010

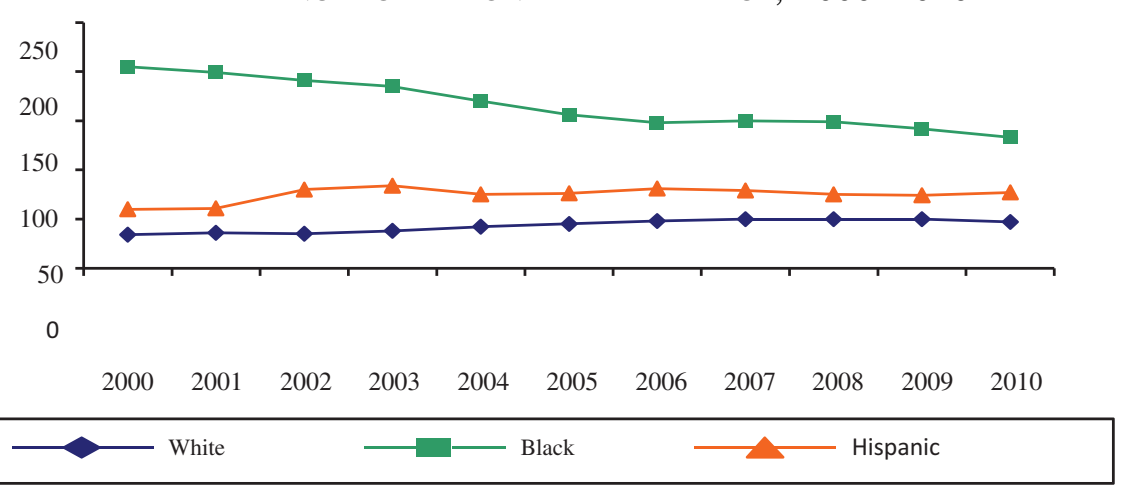

SOURCE: Guerino, P., Harrison, P. M., \& Sabol, W. (2011). Prisoners in 2010. Washington, DC: Bureau of Justice Statistics.

As the rate of incarcerated African American women increases, so too does the number of children with mothers in prison. An additional inhumane element to this statistic is that most prisons allow women prisoners to be shackled during the labor process. As of 2012, African American women between the ages 18-19 were three times more likely to be imprisoned than white women. Hispanic women in this age group had imprisonment rates nearly twice that of white women. However, African American women and White women imprisonment rates were the closest among prisoners ages 25-39, when African American women were less than twice as likely as white women to be imprisoned (Bureau of Justice).

\section{The Injustice of the Justice System}

A famous comedian once said that he went to court seeking justice and what he found was just us! Today people of color continue to be disproportionately incarcerated, policed and sentenced to death at significantly higher rates than their white counterparts. Racial disparities in the criminal justice system threaten communities of color. There are thousands who are disenfranchised and denied equal access to employment, housing, public benefits, and education (Kerby, 2012). The criminal justice system has a serious impact on the color of mass incarceration. People of color comprise $30 \%$ of the United States population, but account for $60 \%$ of the prison population. The prison population has grown tremendously at a rate of $70 \%$ from 1970 to 2005 . The incarceration rate disproportionately impacts men of color. It is noted that 1 in every 15 African American men and 1 in every 36 Hispanic men are incarcerated in comparison to 1 in every 106 white men (Kerby, 2012).

The Bureau of Justice Statistics indicate that one in three black men can expect to go to prison in their lifetime. This is due to the fact that 
people of color have a disproportionate number of encounters with law enforcement, indicating that racial profiling continues to be a problem. The Department of Justice reported that African Americans and Hispanics were approximately three times more likely to be searched during a traffic stop than white motorists. African Americans were twice as likely to be arrested and almost four times as likely to experience the use of force during encounters with law enforcement. Further studies regarding the injustice in the justice system reveal that the number of women incarcerated has increased by 800 percent over the last three decades. As can be expected, women of color have been disproportionately represented. It is documented that African American women are three times more likely than white women to be incarcerated, while Hispanic women are $69 \%$ more likely than white women to be incarcerated.

Another issue that adds to the injustice of the justice system is that once convicted, African Americas receive longer sentences compared to white offenders. The United States Sentencing Commission stated that in the federal system, African American offenders receive sentences that are $10 \%$ longer than white offenders for the same crimes. It was reported that African Americans are $21 \%$ more likely to receive a mandatoryminimum sentences than white defendants and are $20 \%$ more likely to be sentenced to prison.

The injustice of the justice system rears its ugly head once again in the manner in which people of color are targeted as a result of the war on drugs. As mentioned earlier, this war has far reaching impact in the communities of people of color. It is suggested that drug arrests are a large source of the bodies and business for the criminal justice system. Consideration should be given to the fact that half the arrests these days are for drugs and half of those are for marijuana. Despite the fact that African Americans and white people use marijuana at the same rate, an African American is 3.7 times more likely to be arrested for the possession of marijuana than a white person. The ACLU discovered that African American people were six times more likely to be arrested for marijuana than whites. In all drug arrests between 1980 and 2000 in the United States, African American drug arrests rose dramatically from 6.5 to 29.1 per 1,000 persons. During this same period, the white drug arrest rate barely increased from 3.5 to 4.6 per 1,000 persons (Quiley, 2015). As was mentioned earlier, in looking for justice, there is just us! This is particularly interesting when consideration is given to the fact that once again, the majority of people of color are not incarcerated for violent offenses, but primarily for traffic, property, drug, or public order offenses.

The injustice in the justice system that enhances the color of mass incarceration is the manner in which the justice system is structured. 
When people of color face felony charges they often find public defenders, who all too often are overworked and underfunded and thus not fully available to provide adequate defense. In recent years' public defenders in Kentucky, Louisiana, Missouri, and Pennsylvania were so overwhelmed with cases they refused to represent any new clients. It is noted that the right to counsel, is an inherent aspect of the Fourteenth Amendment and the right to due process. It is not uncommon for public defenders to have more than 100 cases going at the same time. And as a result all too often people of color fearful of the justice system as it is, will accept a plea bargain, when in actuality if justice was given, would have not been imprisoned at all. On the other hand, too many people of color, simply plead guilty with the expectation of receiving a reduced sentence. The fundamental right to a lawyer in the United States should apply to all, and yet, it is given out in a disproportionate rate for people of color. As a result of the injustice handed down by the justice system, there are 600,000 African American men in prison at a rate of five times that of white men.

The question then arises, what does this say about our society that it uses its jails and prisons as the primary detention facilities for the poor, and for black and brown people who have been racially targeted, jailing them with those who are mentally ill and chemically dependent. It makes one give serious consideration to Alexander's suggestion that mass incarceration is the new Jim Crow. One must ask whether or not mass incarceration is a legal means of enforcing de jure segregation in this century? Is mass incarceration of African American men in particular the means by which the future growth of the African American race is limited if not seriously curtailed? It is necessary to consider that the current criminal justice system has several parts that begin with legislators who make the laws, to the police who enforce them, to the courts which apply them, to the jails and prison which house the people of color caught up in the system, to the public and business community who decides to hire, to all of us who turn our heads away. It is imperative that the United States strive toward the elimination of racial disparities inherent to our nation's criminal justice policies and practices. There must be the constitutional protection of the rights of all individuals and not just a few. There must be the actual and realized practice of using the Fourteenth Amendment to benefit all citizens of the United States.

The story remains too much the same, boys and young men of color are subject to more surveillance by police in their neighborhoods, partly by virtue of more often living in high-crime neighborhoods. The continued use of "racial profiling" and the utilization of stop and frisk programs are further enhancing the mass incarceration of people of color! These types of surveillance lead to more injustice for people of color. 
The question arises as to how a check can be instituted to remove the inherent bias found in policing and the justice system as a whole? There continues to be the failure for grand juries to correct the numerous injustices that have been inflicted on people of color! Because of these concerns and numerous others, the perception that police officers can treat communities of color and their individuals with impunity has served to undermine the trust that is necessary for law enforcement to effectively partner with communities.

The issue of the color of mass incarceration raises the question of whether or not mass incarceration is the "New Racism?" This becomes an issue when one considers the far reaching aspects of mass incarceration. The color of mass incarceration lends itself to the issue of whether or not racism is alive and well as an institutionalized concept. Is mass incarceration the method by which people of color are relegated to a second class lifestyle, by being forced to remain in unemployment zones, further perpetuating the continued establishments of ghettos that lead to a spiral of recidivism of the prison population? The matter of the color of mass incarceration provides a façade for the majority culture to continue to ignore the issue of urban blight and crime infested neighborhoods. The color of mass incarceration encourages a "new" and subtler racism in an age when open, public displays of bigotry have been discredited. Sad to say, the issue of the color of mass incarceration provides the majority population with the thought that people of color contribute to their plight of mass incarceration. It is interesting that the majority population continues to build more prisons and less colleges and universities which causes one to wonder if there is an innate expectation that people of color will continue to populate the prisons and not have an impact on the population of universities and colleges in the United States? It is an American cliché that one can dream big in the United States and become anything one desires. Yet, with the color of mass incarceration, it becomes apparent that a myriad of dreams is housed in prison! One can certainly speculate on whether or not the exorbitant cost of incarceration is really worth it. Considering that about $\$ 70$ billion dollars are spent on corrections yearly, prisons and jails consume a growing portion of the nearly $\$ 200$ billion spent annually on public safety.

Race continues to be a subject that many refuse sit down at the conference table and discuss in the United States. The issue of mass incarceration is an issue directly related to race relations in this country. The ongoing effects of the mass incarceration of people of color leads to a discussion pertaining to racism in the United States. Mass incarceration, especially the mass incarceration of people of color directly correlates to the future of families and the continued existence of people of color. Again, as Alexander has proposed, is mass incarceration a code 
name for Jim Crow? It is apparent that the New Jim Crow of mass incarceration of African Americans, Hispanics, and Native American, but especially African Americans, is another means of segregating and demoralizing an entire race. Is mass incarceration of people of color a return to the Black Codes found immediately after the Civil War? Have we really made any gains since the decision of Brown v. Board of Education in 1954? It is becoming apparent that the prison system is another institutional means of subordinating Latino and African American men, thereby ensuring that their social mobility is non-existent. It is apparent when comparing the rate of incarceration for people of color to the number of bachelor, master, and doctoral degrees awarded to young African Americans and Hispanics, that it is more common to find these young men in prison cells rather than in a classroom.

\section{Conclusion}

The color of mass incarceration is unenviably black, brown, red and yellow. The continued incarceration rates and the continued building of more prisons provide a strong indicator that the color of mass incarceration will remain the same. There must be consideration given to the manner in which the justice system continues to fail to provide justice for people of color. The issue of law enforcement in an equitable fashion continues to plague this nation. There must be consideration given to the manner in which people of color are denied equal protection under law when confronted by the justice system. Is the color of mass incarceration a reflection of the majority society preventing the progress of people of color at all cost? One has to in a comical manner wonder if mass incarceration is the response to the fact that people of color are now dominant in all major professional sports, music, cooking, and even reality television shows, so that now the majority population can boast the fact that people of color, men and women dominate the prison population. The prison system has symbolic cultural effects that extend beyond the physical boundaries of the complex organization of procedures, processes, and material institutions that comprise the criminal justice system. Mass incarceration containerizes, legitimizes and grounds perceptions which associate race with criminality. Yet the majority of people of color victimized by mass incarceration are committed for nonviolent offenses. The reduction of the imprisonment of nonviolent offenders by one half could lower correction expenditures by as much as $\$ 16.9$ billion per year! It could be argued that this money could be channeled to public defenders in order to ensure that people of color are afforded their rights under the Fourteenth Amendment of the Constitution and that they are no longer victims of the New Jim Crow. 


\section{REFERENCES}

Aguilar, Danielle Nicole (2015) "Oppression, Domination, Prison: The Mass Incarceration of Latino and African American Men" The Vermont Connection, Vol. 35, Article 2.

Alexander, Michelle. "The New Jim Crow- Mass Incarceration in the Age of Colorblindness." The New Press, 2010.

Carson, E. Ann. "Prisoners in 2013." Bureau of Justice Statistics, September, 2014.

Crutchfield, Robert, and Gregory A. Weeks. "The Effects of Mass Incarceration On Communities of Color." Issues in Science and Technology 32, No.1 (Fall 2015).

"Drug War Facts." Race and Prison, 2014

Ellise, Aria. "Black Is The New Black: Numbers of African American Women in Prison Is Rising." Black Doctor. Org, August 13, 2014.

"Facts About Prisons and People In Prison." The Sentencing Project, January 2014.

"Facts About The Mass Incarceration of People of Color in the U.S." June 19, 2013.

"Incarcerated Women." The Sentencing Project, September 2012.

Irwin, John, Vincent Schiraldi and Jason Ziedenberg. "America's One Million Nonviolent Prisoners." Justice Policy Institute, March, 1999.

Johnson, Jacqueline. "Mass Incarceration: A Contemporary Mechanism of Racialization in the U.S.

Kerby, Sophia. "The Top 10 Most Startling Facts About People of Color and Criminal Justice in the United States." March 13, 2012.

Lee, Helen Elaine. "Making Prisoners Visible: How Literature Can Illuminate The Crisis of Mass Incarceration." Lincoln Memorial University Law Review, December, 2013.

Liberman, Akiva M. and Jocelyn Fontaine. "Reducing Harms to Boys and Young Men of Color from Criminal Justice System Involvement." Urban Institute. February 2015.

McCree, Lisa. "Color Blind or Color Bold? Housatonic Horizons. December, 2015.

NAACP- Criminal Justice Fact Sheet

Quiley, Bill. "40 Reasons Our Jails and Prisons Are Full of Black and Poor People.” June, 2015. 
Snyder, Michael. "Mass Incarceration: Twenty-One Amazing Facts About America's Obsession "Statistics of Incarcerated African American Males." Wikipedia

"Statistics on Women in the Justice System." January, 2014.

Street, Paul. "The Race to Incarceration In The Ages of Correctional Keynesianism." Race, Prison and Poverty.

"The Real Cost of Incarceration in the United States." Prison Legal News, November 2013.

Wagner, Peter. "Incarceration is not an Equal Opportunity Punishment." Prison Policy Initiative. August 28, 2012.

Wildeman, Christopher. "Mass Incarceration." Oxford Bibliographies. April 2012.

Younes, Abraham. "Mass Incarceration and the Color of Injustice." Rice Standard. January 20, 2014. 